\title{
Measuring residential satisfaction: a residential environmental satisfaction scale (RESS)
}

\author{
C. C. M. Adriaanse
}

Received: 15 April 2006/Accepted: 15 March 2007/Published online: 17 July 2007

(C) Springer Science+Business Media B.V. 2007

\begin{abstract}
The aim of this article is to introduce an integrative and more comprehensive approach to measurement of residential environmental satisfaction. Domains of residential environmental satisfaction were empirically examined using techniques for multivariate analysis. Data were mainly drawn from the Housing Demand Survey (WoningBehoefteOnderzoek 2002), an a-select sample of 75,034 respondents that is representative for the population of Dutch residents in 2002. The Housing Demand Survey is one of the most extensive sample surveys in the Netherlands and is held every 4 years. The results of exploratory factor analysis give empirical support for the usefulness of the theoretically proposed three-component model of residential environmental satisfaction. Furthermore, multi-group analysis supports the assumption of similarity of perceived quality of the living situation among people varying in degree of residential environmental satisfaction. Reliability and validity tests confirm that the Residential Environmental Satisfaction Scale-Dutch Language Version (RESS-DLV) is an adequate instrument and that it contributes to the understanding of the perceived quality of the living situation. The measure correlates as expected with various criterion measures. The compact and valid instrument RESS-DLV — and especially its abbreviated version — can be very useful as the dependent or the independent variable variable in research carried out in the Netherlands and other European countries. First pattern detection in satisfaction severity groups indicates that satisfaction with the subdomain 'residential social climate' is the most significant component of overall residential satisfaction.
\end{abstract}

Keywords Residential environmental satisfaction - Multidimensional outcome measure $\cdot$ Residential social climate $\cdot$ Reliability

C. C. M. Adriaanse ( $\square)$

OTB Research Institute, Delft, Netherlands

e-mail: C.C.M.Adriaanse@tudelft.nl 


\section{Introduction}

A recent trend in policy-oriented urban research is to make an inventory of problems at the local level and then classify neighborhoods along those lines. Local and national government can then use the results to hammer out urban regeneration policies. These neighborhood profiles are generally derived from objective measures and socio-demographic predictors of dysfunction and dissatisfaction (RIGO 1995; http://www.communities.gov.uk). While moving in a promising direction, the research has run into some conceptual challenges. One of these involves the construction of indicators. They consist of social and physical variables as well as objective and subjective data. Due to their composite nature, the indicators combine the underlying causes of neighborhood decline with its diverse manifestations.

Some progress has been made, especially in analyzing the issues, formulating policy, refining the definitions, and classifying the problems. Nonetheless, stakeholders frequently take too narrow a focus in their approach to declining neighborhoods (see Buys 2002). Countless policy programs define neighborhoods as 'problematic' on the basis of their external appearance. They are characterized by a specific urban planning structure and the predominance of certain housing types (Kruythoff and Haars 2002). Yet not every older mid-rise area should be cast as a problem neighborhood. Look at the statistics. The outliers show that neighborhoods with the same initial urban planning structure can develop in a completely different direction. Thus, one may end up in the 'problem' category while another will not. These neighborhoods got off to an equal start as potential environments. Over time, differences in use and management imbued them with very different capacities to become effective environments (Gans 1968; Van der Horst et al. 2002). Some of the key explanatory factors lie in the spheres of interpretation, social structure of the environment, management, and use of the neighborhood by its residents (BloklandPotters 1998). These factors are critical to an understanding of why one area turns into a problem neighborhood while another does not, even though they are both of the same urban planning type.

Residents' opinions about their neighborhood offer important insights. They shed light on which aspects of the setting have a greater impact on overall residential environmental satisfaction. This line of reasoning was set forth long ago by Herbert Gans, who stated that "The effective environment may thus be defined as that version of the potential environment that is manifestly or latently adopted by users" (Gans 1968, p. 8). This definition has since been operationalized by Diener and Suh (1997). They say that to understand the well-being of an individual, one must measure the person's emotional and cognitive reactions to his/her environment. Taking their cue, the present study focuses on the perspective of the residents. Data was collected on their perception of how successful their neighborhood was. The research described in this article explored the relationship between the individual and the environment at the neighborhood level.

First of all, this article describes the development and validation of a multidimensional outcome measure for residential environmental satisfaction. This measure could serve as the dependent or as the independent variable in future research models. Ultimately, these models should elucidate whether subsets of 
residents tend to use different standards for evaluating their residential environment. Furthermore, they might reveal which neighborhood characteristics have a positive influence on residential satisfaction and which do not. Thus far, few studies have explored how attributes of the residential environment influence residential satisfaction. In the absence of selection criteria, the research has been based on mere lists of physical and social neighborhood characteristics that influence residential satisfaction. For instance, the literature reports on traffic noise, the presence of green space and services, the proximity of social relations, and nuisance such as rubbish (Van Poll 1997; Bonaiuto et al. 1999). But little is known about the interactions between these features.

Second, this article considers the extent to which overall residential satisfaction is explained by the three components of the residential environment distinguished by Canter and Rees (1982), namely neighborhood, house, and neighbors. Thus far, little is known about the mutual interaction of these components. The insights emanating from the analysis may help housing associations - as well as other stakeholders that are developing urban, housing, and neighborhood renewal policy-find the right policy mix to improve overall quality of life.

The following section presents the theoretical framework, and the third section describes the data and methods used. The fourth section expands on the Residential Environmental Satisfaction Scale-Dutch Language Version (RESS-DLV) and its shorter version (the abbreviated RESS-DLV). Both are based on the data of the Dutch national housing sample Housing Demand Survey 2002. The fifth section summarizes the initial outcomes of the multivariate analyses that were performed to determine which of the three subdomains dominates overall satisfaction. The concluding section contains a discussion, policy recommendations, and suggestions for further research.

\section{Residential environmental satisfaction: state of the art}

Certain types of neighborhoods are considered more problematic than others due to their physical characteristics. Residential environments can be typified by objective criteria such as building period, architectural style, spatial structure, amount of green space, and geographic location. The allocation of neighborhood characteristics is not generally disputed. But there are differences in the way residents perceive and use their environments.

The 'iron variables' of household composition, income, and age are generally set off against housing characteristics and the physical characteristics of the neighborhood type. The relations this reveals are used to explain differences in residential satisfaction. But this standard approach has recently been questioned. Apparently, residents evaluate their living environment on the grounds of soft criteria too. Consequently, residents with a similar household composition may evaluate their living environment differently (Karsten et al. 2006). A focus on objective personenvironment relations or objective neighborhood characteristics gives only a limited perspective on the determinants of residential environmental satisfaction. Though fundamental to any understanding of location preferences, this narrow perspective 
excludes the experiential dimension of housing (Altman and Low 1992). Over time, people develop a sense of 'dwelling' or 'being in place'. Their habitual routines build up a cognitive awareness of the residential environment to the point that a person becomes psychologically fused with it.

Galster and Hesser assert that, "Given a set of felt needs and aspirations, an individual evaluates his or her current housing situation with regard to both the dwelling unit and neighborhood." Those needs and aspirations are comprised of individual characteristics (e.g., social class, life cycle stage) and cultural norms (Galster and Hesser 1981, p. 737). Taking this as a point of departure, the outcome of an instrument like the RESS-DLV (described in this article) may be expected to differ by the type of resident. At a higher level of aggregation, the outcome may be expected to differ among countries as a consequence of specific housing-market characteristics and socio-cultural traditions.

The empirical studies dealing with residential satisfaction take one of two approaches (Weidemann and Anderson 1985). Some (e.g., Speare 1974; Newman and Duncan 1979) consider residential satisfaction as a predictor of behavior. It can predict behavior such as moving house or home improvement (Priemus 1986). This approach assumes that any incongruence between the set of needs and aspirations and the current residential status can be alleviated either by moving or making adjustments to the current unit or location (Galster 1987a; Wolpert 1984). Accordingly, studies dealing with residential mobility and its consequences use residential satisfaction as a predictor of moving/coping behavior.

The other approach uses residential satisfaction as a criterion of residential quality (Marans and Rodgers 1975; Galster and Hesser 1981; Bonaiuto et al. 1999; Amérigo and Aragonés, 1990, 1997; Parkes et al. 2002; Pinquart and Burmedi 2004). The researchers seek to establish the factors-both those of the residential environment and those of the individual-that determine the degree to which a person is satisfied with his or her residential environment. Factors such as length of residence, tenure status, the physical characteristics of the house and neighborhood, social bonds, and the socio-demographic characteristics of residents are said to affect satisfaction levels (Galster and Hesser 1981). A new direction within this approach started with the study of housing satisfaction by Canter and Rees (1982). They used multi-dimensional scaling and developed a general model of housing satisfaction that places user goals at the center of the evaluation of the residential environment. They argue that user assessment should form the cornerstone for evaluation research and that 'feedback' or 'appraisal' is integral to the design process (Canter and Rees 1982, p. 185, 186).

Some investigators use a single-item measure of satisfaction with housing conditions. Hadden and Leger (1990, p. 31), for example, asked "Is this neighborhood better, worse, or about the same as your last neighborhood?" Others consider this measure too coarse to represent the full range of residential satisfaction (e.g. Pinquart and Burmedi 2004). Many surveys ask which qualities people associate with a good housing environment and most surveys are presented to a random sample of residents. The typical procedure is to prepare a list of potentially desirable qualities such as 'convenient public transport' or 'a friendly place'. The residents are supposed to indicate whether or not they appreciate these features and 
to express their opinion by using a rating scale. The scale they are given may elicit priorities (How important is it for a neighborhood to have each of the following qualities?) or degree of satisfaction (How satisfied are you with your present neighborhood?).

Numerous empirical studies have examined characteristics of the users (either cognitive or behavioral) or of the environment, both physical and social. But few have organized these variables in a model in an effort to facilitate analysis of the relationships among these characteristics (Parkes et al. 2002). Amérigo and Aragonés (1990, 1997), Amérigo (2002) state that once the objective attributes of the residential environment have been evaluated, they become subjective. At that point, these attributes give rise to a certain degree of satisfaction. Naturally, subjective attributes are influenced by 'personal characteristics', which include one's socio-demographic profile. But subjective attributes are also influenced by one's 'residential quality pattern'. This brings a normative element into the picture, since the individual is asked to compare his/her real and ideal residential environments. The result of this evaluation constitutes a measure of residential satisfaction. It is defined as a positive affective state that the individual experiences towards his/her residential environment and that will cause him/her to behave in certain ways in order to maintain or increase congruence with that environment.

A case in point is a study aimed at deriving the predictors of residential satisfaction in public housing of the city of Madrid (a study conducted by Amérigo et al.). The results show that psycho-social aspects such as relationships with neighbors and the degree of attachment to the residential environment are stronger predictors than physical features such as infrastructure and equipment of the house and neighborhood (Amérigo and Aragonés 1990, p. 323). Other researchers (Canter and Rees 1982) established a working model to measure perceived residential quality. Their model distinguishes three essential elements of the residential environment: the neighborhood, the house, and the neighbors (Canter and Rees 1982, p. 190-192).

The notion of 'residential environmental satisfaction' in the present article is taken as a global attitude of a resident (or a household) towards the living environment. The following sections represent an attempt to use the theoretical insights mentioned above to develop an outcome measure for the purpose of evaluating residential environmental satisfaction. First the data and method are described.

\section{Data and methods}

The analysis is based on Dutch survey and registry data. The results of the 2002 national housing survey (Housing Demand Survey 2002) were used along with data on the characteristics of the Dutch housing stock at the zip-code level. The latter were derived from the Woningmarktmonitor (ABF 2003) and the Wegener data file (2002). The Housing Demand Survey 2002 comprises an a-select sample of 75,034 respondents. The sample is representative for the population of the Netherlands in 2002. The Housing Demand Survey, which is the successor of the general census of 
housing and population, has been held every 4 years since 1964 . The results are used to develop government policy. The Housing Demand Survey provides information about household composition, housing situations, affordability, demand, and residential mobility. The survey includes questions on how residents feel about their living situation: about their evaluation of the current dwelling, their contacts with neighbors, and the appearance of the neighborhood. The theoretical insights mentioned above provided a framework for the initial selection of variables from the questionnaire of the Housing Demand Survey. The selection criteria were refined in light of the present author's own research in two mid-rise neighborhoods in Amsterdam and The Hague (Adriaanse 2004a, b). That research yielded insight into the factors contributing to the success of the neighborhoods from the residents' point of view. The factors they identified referred to physical and spatial characteristics of their neighborhood as well as to its socio-cultural attributes.

Table 1 gives an overview of the Housing Demand Survey variables (translated from Dutch) that were selected for the analyses. Those questions that posed an undesirable situation - the ones with an *-were later recoded in order to use them in subsequent multivariate analyses.

Residents had to give an answer in one of the following two forms: either 'Do you agree with the following statements?' or 'How satisfied are you with...?' The respondents were asked to choose their answer from a five-point Likert scale (1-5) that was constructed as follows for the first form: (1) strongly agree; (2) agree; (3) neither agree nor disagree; (4) disagree; (5) strongly disagree. For the second form, the scale was as follows: (1) very satisfied; (2) satisfied; (3) neither satisfied nor dissatisfied; (4) dissatisfied; (5) very dissatisfied.

Table 1 The 18 Housing Demand Survey items used in the analysis

\footnotetext{
1. I am satisfied with my dwelling

2. The layout of this dwelling is convenient

3. The dwelling is poorly maintained*

4. The dwelling has a pleasing ambience

5.The dwelling has enough outdoor space (balcony, garden)

6. I am satisfied with my living environment

7. The buildings in this neighborhood are attractive

8. Living in this neighborhood is annoying*

9. I feel an urge to move out of this neighborhood*

10. I feel attached to this neighborhood

11. I feel at home in this neighborhood

12. I have a lot of contact with my neighbors

13. I have a lot of contact with other residents in my neighborhood

14. I feel co-responsible for the livability in this neighborhood

15. In this neighborhood residents treat each other pleasantly

16. I live in a cozy neighborhood with a lot of cohesion

17. People in this neighborhood hardly know each other*

18. I am satisfied with the social mix of the neighborhood population
} 


\section{The development of the residential environmental satisfaction scale-DLV}

Explorative factor analysis was used to develop the Residential Environmental Satisfaction Scale-Dutch Language Version (RESS-DLV). Before conducting that factor analysis, though, the inter-item correlation matrix of the 18 Housing Demand Survey items listed in Table 1 were carefully examined. The correlation of 'The dwelling has enough outdoor space' with all other RESS items was between 0.09 and 0.28 . The correlation of ' $I$ feel co-responsible for the livability in this neighborhood' with all other RESS items was between 0.09 and 0.24 . Because the correlation of these items with all the other items is low, it was decided to exclude these two items from further analysis.

The remaining 16 Housing Demand Survey questions were used in an unforced exploratory factor analysis with Varimax rotation. The factor analysis resulted in three factors; see Table 2 for the rotated factor loadings.

Together the three factors accounted for $52 \%$ of the variance. The three factors (domains) were inspected and defined as described below.

Factor 1 can be interpreted as the residents' general opinions and feelings about living in the neighborhood. It represents their experience of the physical environment and the population characteristics. This factor is therefore labeled 'internal neighborhood reputation' (see for example Suttles 1972; Reitzes 1983; Wacquant 1993; Hortulanus 1995). The value attached to a neighborhood is expressed in both internal and external image-forming processes. The perception of

Table 2 Rotated component matrix ${ }^{\mathrm{a}}$

\begin{tabular}{|c|c|c|c|}
\hline & Comp. 1 & Comp. 2 & Comp. 3 \\
\hline 1. I feel at home in this neighborhood & .732 & & \\
\hline 2. I am satisfied with my living environment & .727 & & \\
\hline 3. Living in this neighborhood is not annoying* & .718 & & \\
\hline 4. I am satisfied with the social mix of the neighborhood population & .647 & & \\
\hline 5. I don't feel an urge to move out of this neighborhood* & .588 & & \\
\hline 6. The buildings of this neighborhood are attractive & .539 & & \\
\hline 7. In this neighborhood residents treat each other pleasantly & .528 & & \\
\hline 8. I feel attached to this neighborhood & .511 & & \\
\hline 9. I have a lot of contact with other residents in my neighborhood & & .816 & \\
\hline 10. I have a lot of contact with my neighbors & & .764 & \\
\hline 11. I live in a cozy neighborhood with a lot of cohesion & & .666 & \\
\hline 12. People in this neighborhood tend not to know each other* & & .634 & \\
\hline 13. I am satisfied with my dwelling & & & .732 \\
\hline 14. The layout of this dwelling is convenient & & & .689 \\
\hline 15. The dwelling has a pleasing ambience & & & .676 \\
\hline 16. The dwelling is properly maintained* & & & .652 \\
\hline
\end{tabular}

Extraction method: Principal component analysis. Rotation Method: Varimax with Kaiser normalization. Rotation converged in six iterations

a Those questions that posed an undesirable situation - the ones with an asterisk * - were recoded in order to use them in subsequent multivariate analyses 
the general public and the opinions of stakeholders make up the neighborhood's external reputation; the image that the residents have is its internal reputation.

Factor 2 is labeled 'social climate'. The social climate of a residential environment is an individual's perception of how others treat him or her, one another, and the spatial artefacts within the area that the individual experiences as his or her living environment (Adriaanse 2005).

Factor 3 is labeled 'dwelling satisfaction'.

\subsection{Reliability}

Reliability is the most fundamental aspect of sociological measurement. There would be no reason to assess the validity of the RESS-DLV if its reliability could not be established first. Multivariate analyses were performed on the data obtained with the RESS-DLV in order to assess the instrument's reliability. Cronbach's alpha provides a reliability estimate that simultaneously considers all possible ways of splitting the test items in an inter-item correlational matrix. The degree of reliability was considered to be acceptable when Crohnbach's alpha $>0.70$ (Field 2000). The coefficient alpha of the RESS-DLV was high, 0.86, suggesting that, on the whole, the 16 scale items measure the same construct. The next step was to build subscales based on the three resulting factors and to consider the reliability of each subscale separately. Subscale 1, 'internal neighborhood reputation' (INR), contains the first eight items shown in Table 2. The result of the reliability analysis shows Crohnbach's alpha $=0.82$. Thus, the internal consistency of the 'internal neighborhood reputation' subscale is quite high.

Subscale 2, 'social climate' (SC), contains items 9 through 12. The result of the reliability analysis shows Crohnbach's alpha $=0.75$. Thus, the internal consistency of the 'social climate' subscale is satisfactory. Subscale 3, 'dwelling satisfaction' (DS), contains items 13 through 16. The internal consistency of the 'dwelling satisfaction' subscale is satisfactory, as the result of the reliability analysis shows Crohnbach's alpha $=0.68$. This figure is rather low, partly because so few items are included in this subscale. Overall, the reliability findings for the RESS-DLV and the separate subscales are encouraging. ${ }^{1}$

\subsection{Abbreviated RESS-DLV scale}

To make an outcome measure like the RESS-DLV more suitable for policy research, it should be as compact as possible. For governments and other stakeholders it is less time consuming and less expensive to add a restricted set of items to an existing monitor or survey questionnaire. To that end, ways were sought to construct an abbreviated version of the RESS-DLV. Specifically, the population sample was divided in two groups by dichotomizing the whole database on the fourth quartile. One group consists of residents who are very dissatisfied

\footnotetext{
1 The following values were found for the RESS-DLV total scale: mean 35; median 33; modus 28; $\min / \max 16$ and 76. For subscale 1, 'internal neighborhood reputation', the values are as follows: mean 17; median 16; modus 14; $\min / \max 8$ and 38. For subscale 2, 'social climate': mean 10; median 10; modus 7; $\min / \max 4$ and 19. For subscale 3, ‘dwelling satisfaction': mean 7; median 7; modus 7; min/max 4 and 19.
} 
(fourth quartile); the other comprises all other residents. The aim is to construct an abbreviated scale that can adequately classify most of the dissatisfied respondents.

The assumption underlying discriminant analysis is that each of the variables is normally distributed. In that light, it was necessary to test the hypothesis that all group variances are equal and that the samples come from normal populations. The normal probability plots suggest a departure from normality for each group. The assumptions that must be met to use a discriminant analysis are thus violated. Consequently, the decision was made to devise a binary logistic regression model.

The model tests the extent to which the 16 items in the RESS-DLV matrix are associated with overall neighborhood satisfaction, as measured by the RESS-DLV scale. The two groups of residents - the 'very dissatisfied' and 'all others' — serve as dependent variables in the regression model. The variables (the 16 scale items) are entered (forward) stepwise in the analysis. The results may be summarized as follows. The abbreviated scale correctly classifies extremely dissatisfied respondents in $85 \%$ of the cases correctly, with a reduced set of eight items. With the same set of items, $95 \%$ of all cases are predicted correctly. (See Table 3 for details on the eighth step).

The purpose of abbreviation was to highlight the ability of a restricted number of scale items to predict membership in the $25 \%$ of respondents who are very dissatisfied. With eight scale items, $85 \%$ of the very dissatisfied respondents can be predicted correctly. The abbreviated scale consists of items of all three subscales. The abbreviated scale is highly correlated with the total RESS scale, namely 0.96, which is highly satisfying. The restricted scale containing eight items instead of 16 is much more convenient for research. The eight items included in the abbreviated scale are as follows:

(1) I have a lot of contact with other residents in my neighborhood

(2) I am satisfied with my dwelling

(3) I feel at home in this neighborhood

(4) Living in this neighborhood is not annoying

(5) I don't feel an urge to move out of this neighborhood

Table 3 Logistic regression coefficients of RESS-DLV items most associated with extreme (dis)satisfaction; method forward stepwise. Step summary for eighth step

\begin{tabular}{lrrrr}
\hline Variables in the equation eighth step & B & S.E. & Wald & Sig. \\
\hline I am satisfied with my dwelling & 1.748 & 0.041 & 1846.092 & 0.000 \\
I am satisfied with my living environment & 1.071 & 0.035 & 912.897 & 0.000 \\
I feel at home in this neighborhood & 1.436 & 0.043 & 1119.315 & 0.000 \\
I don't feel an urge to move out of this neighborhood & 1.150 & 0.029 & 1543.369 & 0.000 \\
The buildings of this neighborhood are attractive & 1.119 & 0.032 & 1242.664 & 0.000 \\
In this neighborhood residents treat each other pleasantly & 1.351 & 0.039 & 1187.910 & 0.000 \\
I have a lot of contact with other residents in my neighborhood & 1.445 & 0.038 & 1423.583 & 0.000 \\
I live in a cozy neighborhood with a lot of cohesion & 1.356 & 0.038 & 1268.945 & 0.000 \\
Constant & -28.587 & 0.414 & 4767.580 & 0.000 \\
\hline
\end{tabular}

Nagelkerke $R$-Square 0.852. (Nagelkerke 1991). 
(6) The buildings of this neighborhood are attractive

(7) In this neighborhood residents treat each other pleasantly

(8) I am satisfied with my living environment

The following subsection presents the reliability assessment of the abbreviated RESS-DLV. To assess the reliability of the abbreviated version, the first step was principal component analysis. It revealed one factor explaining $43 \%$ of the variance. For the scale constructed with these eight items, the coefficient alpha was 0.80 , which is satisfactory. ${ }^{2}$

\subsection{Validity}

Several analyses were performed to test the extent to which the RESS-DLV measures what it purports to measure: a resident's satisfaction with the living situation and the neighborhood. Most attention was given to criterion validity. First, as a measure of validity, the mean RESS-DLV score was determined in relation to the criterion 'living in a Dutch postwar mid-rise neighborhood'. When data that link housing variables with deprivation and dissatisfaction are examined, several types of neighborhood-types based on physical characteristics-emerge as more 'problematic' than others. The scientific, social, and policy literature identifies several types as dysfunctional: postwar high-rise neighborhoods and prewar urban renewal areas, but also postwar low-rise areas. Despite historical variations in economic development, housing policy, and socio-cultural traditions, the problems in these types of neighborhood are similar throughout Western Europe. These areas are associated with below-standard living conditions, deprivation, isolated locations, poverty, a negative image, social isolation, pollution, and crime (Prak and Priemus 1984; Heeger 1993; Adriaanse et al. 1997; Schwedler 1998; and Turkington et al. 2004).

The post-World War II mid-rise neighborhood was taken as the gold standard. This type of neighborhood is characterized by the following three conditions:

1. At least half of the housing stock in 2003 was built between 1945 and 1980 .

2. The share of the dwellings in the total housing stock of the zip-code area is at least two standard deviations above the mean percentage of mid-rise flats in all Dutch neighborhoods.

3. The housing stock in the zip-code area is not predominantly (not 50\% or more) of another type. ${ }^{3}$

For the analysis, the zip codes ${ }^{4}$ of register data from the Woningmarktmonitor (ABF 2003) and the Wegener data file were matched with the zip codes of the respondents

\footnotetext{
${ }^{2}$ The findings for the abbreviated RESS-DLV are: mean 16.7; median 16.0; modus 14.0; $\min / \max 8$ and 38 .

3 The zip-code area comprises at least 100 households. The variables for the construction of these criteria were derived from register data of Wegener and the ABF Woningmarktmonitor 2003.

4 Strictly speaking, Dutch 'postcode' areas (called zip-code areas here) do not exactly align with neighborhood boundaries. Nonetheless, this article refers to these zip-code areas as neighborhoods for the sake of convenience.
} 
Table $4 T$-test; group 0 = people who do not live in a postwar mid-rise neighborhood; group $1=$ people who do live in a postwar mid-rise neighborhood

\begin{tabular}{lcrrlll}
\hline & & \multicolumn{1}{c}{$N$} & Mean & Std. Deviation & \multicolumn{1}{l}{ t } \\
\hline Subscale for internal reputation & 0 & 41,687 & 16.9 & 4.4 & -21.0 & 0.000 \\
& 1 & 3,456 & 18.6 & 5.0 & & 0.000 \\
Subscale for social climate & 0 & 54,923 & 10.1 & 2.9 & -17.8 & 0.000 \\
& 1 & 4,378 & 10.9 & 3.0 & & 0.000 \\
Subscale for dwelling satisfaction & 0 & 46,755 & 7.3 & 2.1 & -19.9 & 0.000 \\
& 1 & 3,837 & 8.0 & 2.5 & & 0.000 \\
RESS-DLV & 0 & 35,678 & 35 & 7.5 & -23.1 & 0.000 \\
& 1 & 3,152 & 38 & 8.3 & & 0.000 \\
Abbr. RESS-DLV & 0 & 41,687 & 17 & 4.2 & -23.0 & 0.000 \\
& 1 & 3,456 & 18 & 4.7 & & 0.000 \\
\hline
\end{tabular}

of the Housing Demand Survey 2002 sample. Seven percent $(4,934)$ of the respondents of the Housing Demand Survey live in a zip-code area that can be typified as a postwar mid-rise neighborhood. In total, 116 neighborhoods in the country belong to the category 'postwar mid-rise'. The question is, are the residents of postwar mid-rise neighborhoods significantly more dissatisfied than people who do not live in a neighborhood of this type? A $t$-test shows that the RESS-DLV and its subscales can discriminate well between residents of postwar mid-rise neighborhoods and people living elsewhere. Table 4 shows the mean levels of satisfaction on the RESS-DLV and each of the RESS-DLV subscales for respondents who live in a postwar mid-rise neighborhood and those who do not. The higher the mean score, the more negatively the residents evaluate the fit between their household and their living and housing situation.

Another way of demonstrating that the RESS-DLV measures what it purports to measure is to use all the available information. The first step was the division of the sample in 10 equal groups on the basis of the respondents' scores on the RESSDLV. ${ }^{5}$ The bar chart below shows the 10 deciles. The first decile contains $3 \%$ of the respondents living in postwar mid-rise neighborhoods, while the 10th decile has almost $15 \%$. Assuming that the RESS-DLV is valid, it is expected that the higher the score on the RESS-DLV, the more likely it is that that score comes from someone in a postwar mid-rise neighborhood. The bar chart shows the association between the percentage of persons living in a postwar mid-rise neighborhood and the score on the RESS-DVL (Fig. 1).

The chart clearly shows that the association between living in a postwar mid-rise neighborhood and evaluating the living situation as unsatisfactory has a monotone upwardly climbing tendency. We can conclude that the RESS-DLV measures what it purports to measure. The higher the RESS-DLV score, the more dissatisfied the respondent is.

Tables 5 and 6 present the initial normative data, consisting of the 10 deciles for the population. A norm is a factual outcome score that is used as a criterion to

\footnotetext{
5 The deciles are described in more detail later in the section on norms and distributions.
} 


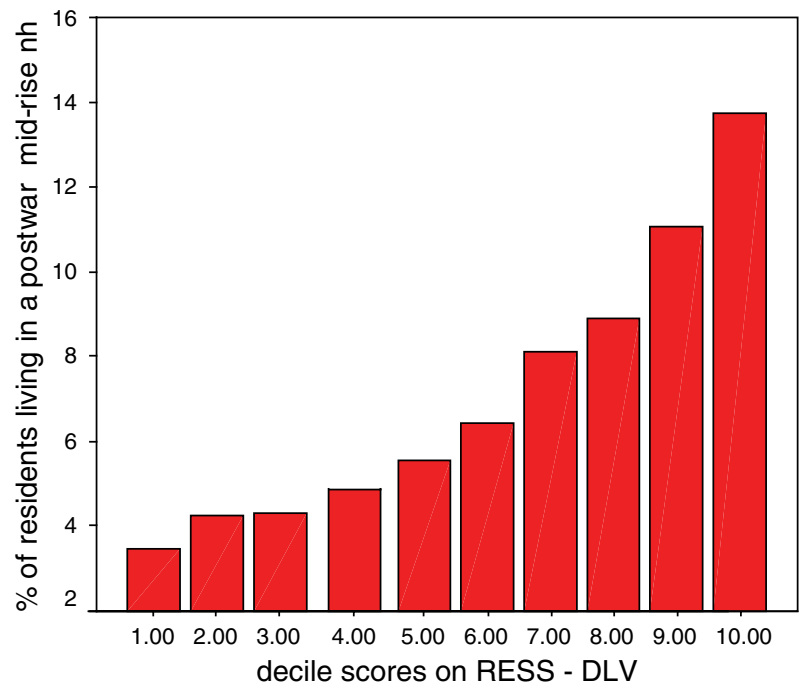

Fig. 1 Bar chart with association between $\%$ of residents living in a postwar mid-rise neighborhood and the score on the RESS-DLV

Table 5 Scores of RESS-DLV deciles

\begin{tabular}{lll}
\hline Decile & Total RESS-DLV score & Degree of satisfaction \\
\hline 1 & 16 through 27 & Extremely satisfied \\
2 & 28,29 & Very satisfied \\
3 & 30 & Far above average satisfied \\
4 & 31,32 & Above average satisfied \\
5 & 33 & Average satisfied \\
6 & 34,35 & Average satisfied \\
7 & 36,37 & Below average satisfied \\
8 & $38,39,40$ & Far below average satisfied \\
9 & 41 through 46 & Very dissatisfied \\
10 & 47 through 76 & Extremely dissatisfied \\
Mean & 34.9 & \\
\hline
\end{tabular}

determine severity. The tables of the range of variation in RESS-DLV scores and its abbreviated version may serve as baseline data for other researchers who may use the RESS-DLV or the abbreviated RESS.

\section{First pattern detection in satisfaction severity groups on the RESS-DLV}

This section describes the first results of a multivariate analysis carried out with the RESS-DLV. They show that the impact of the subscales in overall residential satisfaction varies significantly. In a study by Amérigo and Aragonés, multiple 
Table 6 Scores of the abbreviated RESS-DLV deciles

\begin{tabular}{lll}
\hline Decile & $\begin{array}{l}\text { Total abbr. } \\
\text { RESS-DLV score }\end{array}$ & $\begin{array}{l}\text { Degree of } \\
\text { satisfaction }\end{array}$ \\
\hline 1 & 8 through 12 & Extremely satisfied \\
2 & 13 & Very satisfied \\
3 & 14 & Far above average satisfied \\
4 & 14 & Above average satisfied \\
5 & 15 & Average satisfied \\
6 & 16 & Average satisfied \\
7 & 17 & Below average satisfied \\
8 & 18,19 & Far below average satisfied \\
9 & 20 through 22 & Very dissatisfied \\
10 & 23 through 38 & Extremely dissatisfied \\
Mean & 16.7 & \\
\hline
\end{tabular}

regression analysis revealed that attachment to the neighborhood and relationships with neighbors explained the greatest variance in residential satisfaction (Amérigo and Aragonés 1990, p. 323). In the same vein, the outcomes of the multivariate analyses described in the following sections demonstrate that satisfaction with the social climate in the neighborhood is the most significant factor in overall residential satisfaction in the Netherlands.

The task was to find out which of the subscales dominates within the overall residential environmental satisfaction of Dutch residents (RESS-DLV). The first step was to make the RESS subscales independent of their length. This was done by dividing each subscale by the number of its items. The second step was to divide the sample of residents into four quartiles, ranging from residents who are very satisfied (1) to residents who are very dissatisfied (4). Figure 2 depicts the weighted mean score of each quartile (i.e., group defined by severity of dissatisfaction) on a bar chart.

In view of the extent to which the RESS subscales depart from normality, Friedman's tests were performed to find out which of the three weighted subscales of the RESS predominates in the residential environmental satisfaction of each quartile. The findings lead to the following conclusions. For all quartiles-from people who are (very) satisfied to people who are (very) dissatisfied-overall residential environmental satisfaction is dominated by the perceived social climate of the neighborhood. That aspect is always followed by the internal reputation and, in third place, by dwelling satisfaction. Differences between the (weighted) subscales within each group are always statistically significant, with $P=0.000$. The mean ranks of the subscales were as follows. First quartile: subscale 'social climate' 1.9; subscale 'internal reputation' 1.7; subscale 'dwelling satisfaction' 1.5. Second quartile: subscale 'social climate' 2.4; subscale 'internal reputation' 1.9; subscale 'dwelling satisfaction' 1.7. Third quartile: subscale 'social climate' 2.8; subscale 'internal reputation' 2.1; subscale 'dwelling satisfaction' 1.9. Fourth quartile: subscale 'social climate' 3.3; subscale 'internal reputation' 2.8; and subscale 'dwelling satisfaction' 2.4. 
Fig. 2 The weighted mean score of severity groups on each subscale

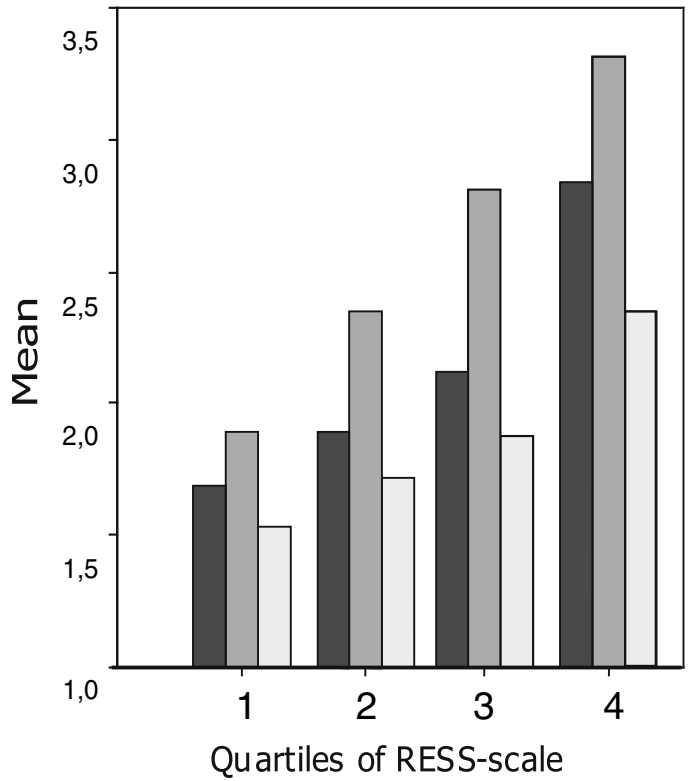

Internal neighborhood reputation subscale

Social climate subscale

Dwelling satisfaction subscale

1 residents who are very satisfied

2 residents who are satisfied

3 residents who are dissatisfied

4 residents who are very dissatisfied

How can these outcomes be interpreted in more general terms? First of all, except for the variance among neighborhood types, the differences reflect general developments in society at large. These changes have influenced the relationship between aspects of the living environment. At the beginning of the 20th century, the quality of the housing stock was far below its current level, both in the Netherlands and in other Western European countries. Consequently, slum clearance was a major policy issue at the time (Van der Horst et al. 2002).

Nowadays, most people in the Netherlands have access to a dwelling of reasonable quality. In the course of time, other aspects of the residential environment have become more important to the perception and evaluation of neighborhoods. For instance, people are now more concerned about the concentration of certain population groups and the accumulation of problems in specific neighborhoods (RIGO 2004). These concerns do not seem to relate exclusively to the quality of the housing stock in these areas; it is plausible that socio-cultural factors play an important part. It is often suggested that a lack of 
social cohesion is an important factor in these problematic neighborhoods (e.g., Kearns and Parkinson 2001).

A recent case study in the Buitenveldert district of Amsterdam-a problem-free area of a vulnerable neighborhood type-expands on this topic. There, it is not the degree of social interaction or social cohesion among the residents that explain their residential satisfaction. Rather, it is the shared social identity and the unwritten rules that explain the favorable social climate in the neighborhood (Adriaanse 2006a, b). Generally speaking, the residents of Buitenveldert do not express satisfaction with their neighborhood in terms of the quality of the dwelling or the aesthetics of the architecture in the surroundings. Instead, they refer first and foremost to the favorable social climate. These research findings support the pattern detected in satisfaction severity groups on the RESS-DLV. Among those groups, satisfaction with the social climate in the neighborhood is significantly the most important element of overall residential satisfaction - unless a resident is either (very) satisfied or (very) dissatisfied.

\section{Conclusion and discussion}

This article first described residential environmental satisfaction as a global attitude of a resident (or household) towards his dwelling, the social climate of the neighborhood and the internal neighborhood reputation. The article then described the development and validation of the RESS-DLV, an instrument to measure residential environmental satisfaction. Though adequate, the instrument can be improved and refined and the subscale for dwelling satisfaction needs to be extended. The first analyses indicated that the RESS-DLV is a valid instrument. It can generate important additional information for policy-making on urban renewal and neighborhoods in general. With the help of the RESS-DLV and its abbreviated version, researchers can offer insight in the degree to which specific neighborhood problems are of most concern-and to whom.

The pattern detection in satisfaction severity groups on the RESS-DLV demonstrated that residential environmental satisfaction is expressed not only by satisfaction with the dwelling or by the internal neighborhood reputation. Rather, it is mainly revealed by people's evaluation of the social climate in their neighborhood. The importance of social climate for residential environmental satisfaction raises interesting questions for follow-up research. For example, further study could identify the ingredients of a satisfying social climate. Does it mean that there are intensive local networks and a close-knit neighborhood community? Or are there other determining factors? Young residents, married couples, female heads of households and large families consistently record less satisfaction with any given housing setting. Moreover, their satisfaction ratings are more strongly tied to perceptions of crime, run-down properties, and the similarity of neighbors (Galster and Hesser 1981). Follow-up research is needed to determine whether these groups differ significantly in their perception of the three subdomains of residential satisfaction. 
The RESS-DLV can help investigators conduct more selective and comparative research on neighborhood life and the conditions for residential environmental satisfaction. So far, little has been published on ways to compensate negatively experienced attributes of the living environment by other residential attributes. The RESS-DLV and its subscales could serve as the dependent or the independent variable in future research models. They could clarify whether subsets of residents tend to apply different standards when evaluating their residential environment.

Follow-up research should also consider the role differences in residential lifestyle play. And the picture would not be complete without the constraints on residential choice that households experience. Both are important mediating factors in the way residents evaluate neighborhood attributes. There is need for more insight into the fact that residents of vulnerable types of neighborhood are satisfied with their housing and living situation. A case study by the author is a first attempt to explore in some depth the differences between successful and problematic neighborhoods of the same vulnerable type (Adriaanse 2004a, b). An interesting benefit of using the Housing Demand Survey data for this purpose is that it is feasible to measure residential environmental satisfaction and the way in which cognition is affected by changes in the environment such as reconstruction. Nowadays, it is possible to conduct longitudinal studies, as the data from the Housing Demand Survey go back over a long period of time.

Finding out which residents are most satisfied or dissatisfied with their neighborhood should provide policy-makers with additional information on where to target their improvement efforts. Comparison of the residents' views with the ways in which other stakeholders (housing associations, municipalities, policymakers) define and interpret a neighborhood's problems and success factors can bring to light any difference of opinion between the stakeholders. A fuller picture could then lead to more precise and probably more effective interventions in neighborhoods.

Acknowledgement The author gratefully acknowledges the financial assistance of the Dutch government through the Habiforum Program Innovative Land Use.

\section{References}

Adriaanse, C. C. M., van de Wardt, J. W., \& Hortulanus, R. P. (1997). Sociale integratie en sociale segregatie in twee Amsterdamse stadsdelen; een onderzoek naar zelfredzaamheid, maatschappelijke participatie en maatschappelijke cohesie in Oud-West en de Spaarndammerbuurt. Utrecht: University Utrecht.

Adriaanse, C. C. M. (2004a). Success factors of neighbourhoods that work. In C. Whitehead (Ed.), ENHR international housing conference: Housing, growth and regeneration (pp. 1-18). Cambridge: University of Cambridge.

Adriaanse, C. C. M. (2004b). Succesfactoren van werkende wijken; een verkennende studie in twee naoorlogse flatwijken. Delft: Onderzoeksinstituut OTB.

Adriaanse, C. C. M. (2005). The utility of the 'social climate' concept in understanding urban neighborhood life: A theoretical approach and initial empirical evidence. In M. van der Land \& L. G. A. J. Reinders (Eds.), Doing, thinking, feeling home: The mental geography of residential environments; International ENHR conference (pp. 1-12). Delft: Onderzoeksinstituut OTB. 
Adriaanse, C. C. M. (2006a). The power of detachment; social contacts and normative cohesion in a Dutch post-war mid-rise neighborhood. In B. Cernic Mali, et al. (Eds.), ENHR conference 2006: Housing in an expanding Europe. Theory, policy, implementation and participation (pp. 1-14). Ljubljana, Slovenia: Urban Planning Institute of the Republic of Slovenia.

Adriaanse, C. M. M. (2006). Publieke familiariteit bindt in Buitenveldert. City Journal, 12, 14-19.

Altman, I., \& Low, S. (Eds.) (1992). Place attachment. New York: Plenum.

Amérigo, M., \& Aragonés, J. I. (1990). Residential satisfaction in council housing. Journal of Environmental Psychology, 10, 313-325.

Amérigo, M., \& Aragonés, J. I. (1997). A theoretical and methodological approach to the study of residential satisfaction. Journal of Environmental Psychology, 17, 47-57.

Amérigo, M. (2002). A psychological approach to the study of residential satisfaction. In J. I. Aragonés, G. Franscescato \& T. Garling (Eds.), Residential environments: Choice, satisfaction, and behavior (pp. 81-99). Westport: Bergin \& Garvey.

Blokland-Potters, T. (1998). Wat stadsbewoners bindt; sociale relaties in een achterstandswijk. Kok Agora: Kampen.

Bonaiuto, M., Aiello, A., Perugini, M., Bonnes, M., \& Ercolani, A. P. (1999). Multidimensional perception of residential environmental quality and neighbourhood attachment in the urban environment. Journal of Environmental Psychology, 19, 331-352.

Buys, A. (2002). Op zoek naar de dimensies van stedelijke vitaliteit: tussen de pijlers van het Grote Steden Beleid. Tijdschrift voor de Volkshuisvesting, nr. 6, 29-33. The Hague: NIROV.

Canter, D., \& Rees, K. (1982). A multivariate model of housing satisfaction. International Review of Applied Psychology, 31, 185-208.

Diener, E., \& Suh, E. (1997). Measuring quality of life: economic, social and subjective indicators. Social Indicators Research, 40, 189-216.

Field, A., (2000). Discovering statistics, using SPSS for windows. London: Sage publications.

Galster, G., \& Hesser, G. W. (1981). Residential satisfaction: compositional and contextual correlates. Environment and Behavior, 13, 735-758.

Galster, G. (1987a) Homeowners and neighborhood reinvestment. Durham, North Carolina: Duke University Press.

Gans, H. J. (1968). People and plans, essays on urban problems and solutions. New York/ London: Basic Books.

Hadden, L., \& Leger, M. for the US Department of Housing and Urban Development (HUD) (1990). Codebook for the American Housing Survey Data Base: 1973-1993. Washington, DC: US Government Printing Office.

Heeger, H. (1993). Aanpak van naoorlogse probleemcomplexen. Delft: Delft University Press.

van der Horst, H., Kullberg, J., \& Deben, L. (2002). Wat wijken maakt, de wording van functionele, expressieve en sociale kwaliteiten van het woonmilieu. The Hague/Utrecht: DGVH/Nethur.

Hortulanus, R. P. (1995). Stadsbuurten. Een studie over bewoners en beheerders in buurten met uiteenlopende reputaties. The Hague: VUGA.

Karsten, L., Reijndorp, A., \& van der Zwaard, J. (2006). Smaak voor de stad, een studie naar de stedelijke woonvoorkeur van gezinnen. The Hague: Ministerie van VROM.

Kearns, A., \& Parkinson, M. (2001). The significance of neighbourhood. Urban Studies, 38(12), 21032110.

Kruythoff, H. M., \& Haars, A. (2002). Herdifferentatie van de woningvoorraad. Inventarisatie Meerjarenontwikkelingsprogramma's G30. Delft: Delft University Press.

Marans, R. W., \& Rodgers, S. W. (1975). Toward an understanding of community satisfaction. In A. Hawley \& V. Rock (Eds.), Metropolitan America in contemporary perspective. New York: Halstead Press.

Nagelkerke, N. J. D. (1991). A note on a general definition of the coefficient of determination. Biometrika, 78(3), 691-692.

Newman, S. J., \& Duncan, G. J. (1979). Residential problems, dissatisfaction, and mobility. Journal of the American Planning Association, 45, 154-166.

Parkes A., Kearns, A., \& Atkinson, R. (2002). The determinants of neighbourhood dissatisfaction, CNR Paper 1.

Pinquart, M., \& Burmedi, D. (2004). Correlates of residential satisfaction in adulthood and old age: A meta-analysis. Annual Review of Gerontology and Geriatrics, 195-222.

Prak, N., \& Priemus, H. (Eds.) (1984). Post-war public housing in trouble. Delft: Delft University Press. 
Van Poll, R. (1997). The perceived quality of the urban residential environment. A Multi-attribute evaluation. Ph-thesis, Groningen: University of Groningen.

Priemus, H. (1986). Housing as a social adaptation process. A conceptual scheme. Environment and Behaviour, 18, 109-131.

Reitzes, D. C. (1983). Urban images. A social-psychological approach. Sociological Inquiry, 53, 314333.

RIGO Research \& Advies. (1995). Naoorlogse wijken in beeld. Wijktypologie en analyse lokale aanpakstrategieën voor woonwijken uit 1946-1980. Amsterdam: RIGO.

RIGO Research \& Advies. (2004). Leefbaarheid van wijken. The Hague: Ministerie van VROM.

Schwedler, H. U. (Ed.) (1998). A future for large housing estates. Berlin: The Urban Environment in Europe.

Speare, A. Jr. (1974). Residential satisfaction as an intervening variable in residential mobility. Demography, 11(2), 173-188.

Suttles, G. D. (1972). The social construction of communities. Chicago and London: University of Chicago Press.

Turkington, R., van Kempen, R., \& Wassenberg, F. (2004). High-rise housing in Europe. Current trends and future prospects, Housing and Urban Policy Studies 28. Delft: Delft University Press.

Wacquant, L. (1993). Urban outcasts: Stigma and division in the black American ghetto and the French urban periphery. International Journal of Urban and Regional Research, 17, 366-383.

Weidemann, S., \& Anderson, J. R. (1985). A conceptual framework for residential satisfaction. In I. Altman \& C. H. Werner (Eds.), Home environments. New York: Plenum Press.

Wolpert, J. (1984). Verhuizen als besluitvormingsproces: keuze en dwang. In H. Priemus (Ed.) Verhuistheorieën en de verdeling van de woningvoorraad. Delft: Delft University Press. 